
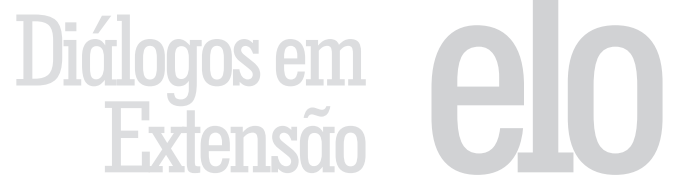

\title{
Difusão de híbridos de milho para comunidades de agricultura familiar
}

Magno Antonio Patto Ramalho ${ }^{1}$, Carlos Eduardo Caixeta de Castro ${ }^{2}$, Jose Maria Villela Padua ${ }^{3}$, Gustavo Andrade Cardoso ${ }^{4}$, Marcio Edgar Rodrigues Leite ${ }^{5}$, Edson Spini Logato ${ }^{6}$, João Cândido de Souza

RESUMO: O presente trabalho teve como objetivo evidenciar a experiência de difusão de cultivares híbridas de milho para a agricultura familiar. A atividade foi realizada na comunidade dos "Coelhos" no município de Itumirim. Constatou-se que o contato dos professores e estudantes com a comunidade foi muito útil pela troca de experiência. Já os agricultores se beneficiaram pelos grãos e sementes que eles produziram e também por algumas tecnologias que eles poderão implementar no futuro.

Palavras chave: Agricultura familiar, cultivar híbrida, melhoramento participativo.

Áreas temáticas: Relato de experiência e tecnologia

\footnotetext{
${ }^{1}$ Magno Antonio Patto Ramalho; Universidade Federal de Lavras, magnoapr@dbi.ufla.br

${ }^{2}$ Carlos Eduardo Caixeta de Castro; Universidade Federal de Lavras, carloscaixetaagro@hotmail.com

3 Jose Maria Villela Padua; Universidade Federal de Lavras, zepao@hotmail.com

${ }^{4}$ Gustavo Andrade Cardoso; Universidade Federal de Lavras, gustavoancardoso@hotmail.com

${ }^{5}$ Marcio Edgar Rodrigues Leite; Emater - MG, itumirim@emater.mg.gov.br

${ }^{6}$ Edson Spini Logato; Emater- MG

7 João Cândido de Souza; Universidade Federal de Lavras, cansouza@dbi.ufla.br
} 


\section{Diffusion of hybrid corn for family farming communities}

ABSTRACT: This study aimed to highlight the experience of maize hybrid diffusion for family farming. The activity took place in the community of "Coelhos" in the city of Itumirim. It was found that the contact between teachers and students with community was very useful as an exchange of experiences. The farmers have benefited from the grains and seeds that they produced and also by some technologies that they can use in the future.

Keywords: Family farming, maize hybrid, improviment of participation.

Thematic area: technology

\section{La difusión del maíz híbrido para las comunidades agríco- las de la familia}

RESUMEN: Este estudio tuvo como objetivo destacar la experiencia de difusión de cultivares de maíz híbrido para la actividad de la agricultura familiar e se llevó a cabo en la comunidad de "Coelhos" en la ciudad de Itumirim. Encontró que el contacto entre los profesores y estudiantes con la comunidad fue muy útil para el intercambio de experiencias. Ya los agricultores se han beneficiado de los granos y las semillas que producen y también algunas tecnologías que se pueden implementar en el futuro.

Palabras claves: Agricultura familiar, maíz híbrido, mejor participacion.

Área temática: técnicas 


\section{INTRODUÇÃO}

O Sul do estado de Minas Gerais é uma das mais importantes regiões produtoras de milho do Brasil. Embora existam grandes empresas rurais, a maioria da produção é proveniente da agricultura familiar. Esses últimos agricultores têm dificuldades de utilizar algumas tecnologias devido ao custo. Uma dessas tecnologias são sementes híbridas que são comercializadas na região. Por essa razão, normalmente, os grãos colhidos na safra anterior são reutilizados como semente. Nessa condição, a produtividade é reduzida (Hallauer et al., 2010), com prejuízo para as suas famílias.

As sementes comercializadas são híbridos simples, triplos ou duplos. Esses híbridos são obtidos a partir do cruzamento de duas ou mais linhagens (Paterniani e Campos, 1999). A obtenção dessas linhagens é um processo demorado e caro. Por isso, a Universidade Federal de Lavras (UFLA), há alguns anos, desenvolveu uma metodologia com a qual os próprios produtores podem produzir suas sementes e obter produtividade comparável à das sementes híbridas comercializadas (Souza Sobrinho et al., 2001).

Considerando a área que cada agricultor cultiva anualmente, não justifica individualmente produzir a própria semente. Deve ser uma atividade comunitária. Para avaliar a viabilidade de se utilizar comunidade de agricultores familiares na produção de sua própria semente híbrida, foi realizada esta atividade de extensão universitária.

\section{METODOLOGIA}

Aqui será relatado o caso de apenas uma comunidade, embora o trabalho tenha sido realizado em outras comunidades da região. A comunidade selecionada pelo serviço de extensão do município de Itumirim (MG), distrito de Macuco, foi a dos "Coelhos". Essa é uma comunidade que tem como foco uma grande família, mas há também outros agricultores que têm como interesse comum manter a tradição, como a de utilizar o carro de boi como meio de transporte.

Professores e alunos da UFLA e o técnico da EMATER entraram em contato com a comunidade e discutiram como seria realizado o trabalho. Foi enfatizado que a UFLA acompanharia a implantação, condução e colheita do milho, mas todas as atividades seriam realizadas pelos próprios agricultores.

As atividades foram divididas em três partes. A primeira envolveu uma unidade demonstrativa (UD) de avaliação de sete híbridos, sendo seis experimentais do programa da UFLA e uma testemunha, 
o híbrido duplo mais semeado na região, o AG 1051. Essa unidade demonstrativa teve como objetivo realizar o denominado melhoramento participativo, em que os agricultores, junto com os professores e estudantes da UFLA, identificaram o híbrido a ser sintetizado na próxima safra. $\mathrm{Na}$ UD, os híbridos foram semeados em três linhas de 120 metros de comprimento, no espaçamento de $80 \mathrm{~cm}$ entre linhas, com seis sementes por metro. Os demais tratos culturais foram aqueles normalmente utilizados na região. Na colheita, foram tomadas na linha central três amostras de quatro metros. De cada amostra, foi obtido o número de plantas e produção de grãos.

A segunda atividade foi a semeadura do híbrido experimental UFLA 2, na mesma época da UD, em uma área maior. Desse modo, os agricultores puderam avaliar o comportamento desse híbrido, cujas sementes estavam sendo produzidas por eles.

A terceira atividade foi a instalação do campo de produção de sementes propriamente dito, em uma área de 0,8 ha. Esse foi semeado no mesmo local, porém com o isolamento de 33 diês. A semeadura foi presenciada pelos agricultores onde foi explicado que seriam semeadas duas linhas como doadoras de pólen (macho) e quatro linhas como receptoras de pólen (fêmea). As linhas de macho e as linhas de fêmea são populações em equilíbrio de Hardy \& Weinberg derivadas de híbridos simples que possuem boa heterose quando cruzadas. A semeadura foi realizada com uma semeadora de três linhas, sendo que, em um dos depósitos foram acondicionadas as sementes da população macho e nos outros dois, as sementes da população fêmea. Os tratos culturais foram semelhantes ao da cultura na região. Pouco antes de iniciar o florescimento do milho, a inflorescência masculina foi retirada, ou seja, procedeu-se a emasculação das linhas fêmeas. Essa operação foi realizada por estudantes da UFLA junto com a comunidade.

\section{RESULTADOS}

Na Tabela 1 são apresentadas as médias dos híbridos experimentais para o caráter produtividade. Pode-se observar que todos os híbridos tiveram desempenho semelhante. Em princípio, poder-se-ia argumentar que a produtividade fora baixa. É preciso salientar que esse local foi uma área de pasto depauperada, e a calagem foi realizada muito próxima à semeadura, o que deve ter contribuído para que a produtividade não pudesse ser maior. Vale salientar que, segundo informações dos agricultores, a produtividade obtida foi muito superior à que eles obtêm normalmente. Além disso, observa-se que a produtividade obtida foi superior à média nacional de 4,6 t.ha ${ }^{-1}$ (CONAB, 2012). É expressivo o fato do desempenho dos 
híbridos experimentais serem semelhantes ao da testemunha AG 1051. Esse híbrido duplo é o mais semeado na região.

A área demonstrativa de produção de grãos do híbrido UFLA 2 foi muito produtiva. Por ocasião da colheita, no mês de maio, a comunidade se organizou para transportar o milho em vários carros de boi até a cidade e aproveitaram o momento para realizar a primeira festa do carro de boi de Macuquinho (Figura 1).

No campo de produção de sementes, tudo correu como planejado, o despendoamento foi realizado com êxito e os agricultores puderam visualizar a facilidade do procedimento. As sementes colhidas foram classificadas, embaladas e distribuídas aos agricultores. Parte será também distribuída para outros agricultores de comunidades próximas em um sistema de troca. Ou seja, troca de semente por grão colhido na safra seguinte.

Tabela 1: Produtividade média de grãos de milho ( $\mathrm{kg} / \mathrm{ha}$ ) obtida na unidade demonstrativa de híbridos duplos de milho, na comunidade dos Coelhos, no município de Itumirim (MG) 2010/1011.

\begin{tabular}{|c|c|}
\hline Híbridos & $\mathrm{Kg} / \mathrm{ha}$ \\
\hline UFLA 1 & 4041 \\
\hline UFLA 2 & 5166 \\
\hline UFLA 3 & 5441 \\
\hline UFLA 4 & 4994 \\
\hline UFLA 5 & 5855 \\
\hline UFLA 6 & 5372 \\
\hline Test. (AG - 1051) & 5648 \\
\hline
\end{tabular}

Foi realizado um dia de campo envolvendo os agricultores da região, estudantes de graduação, pós-graduação e professores da UFLA. Nesse dia de campo, foram apresentados os resultados obtidos na Unidade Demonstrativa e discutido como deve ser efetuado o despendoamento. Os agricultores fizeram inúmeros questionamentos e comentários, o que possibilitou a melhor interação entre a pesquisa agrícola e seus usuários. O representante da comunidade assim se expressou "este contato que tivemos com os professores e estudantes da UFLA nos proporcionou a troca de experiência e mais do que isso, possibilitou identificar os problemas de nossas lavouras de milho, feijão, etc. Portanto, fomos beneficiados por algumas tecnologias de manejo que iremos utilizar nas próximas plantações."

\section{DISCUSSÃO}

A experiência foi muito salutar. Professores, alunos de graduação e de pós-graduação da Universidade tiveram a chance de viven- 
ciar na prática o processo de difusão de uma nova cultivar. Adicionalmente, foi possível acompanhar os agricultores durante todas as etapas do processo, desde a semeadura ao transporte da produção por meio de carros de boi. Foi possível "in loco" ver como o agricultor visualiza a Universidade e o produto por ela produzido.

Os agricultores da comunidade por sua vez tiveram a oportunidade de ver como é produzida a semente híbrida de milho e algumas técnicas de manejo da cultura que eles poderão utilizar, reduzindo o trabalho e contribuindo para o aumento da produtividade.

O acompanhamento da comunidade terá continuidade na próxima safra. Nesse caso, será dada ênfase à implantação do novo campo de produção de semente. $\mathrm{O}$ desempenho da cultivar em outras propriedades será verificado, sempre procurando ter a opinião dos agricultores a respeito da mesma e do próprio manejo da cultura do milho.
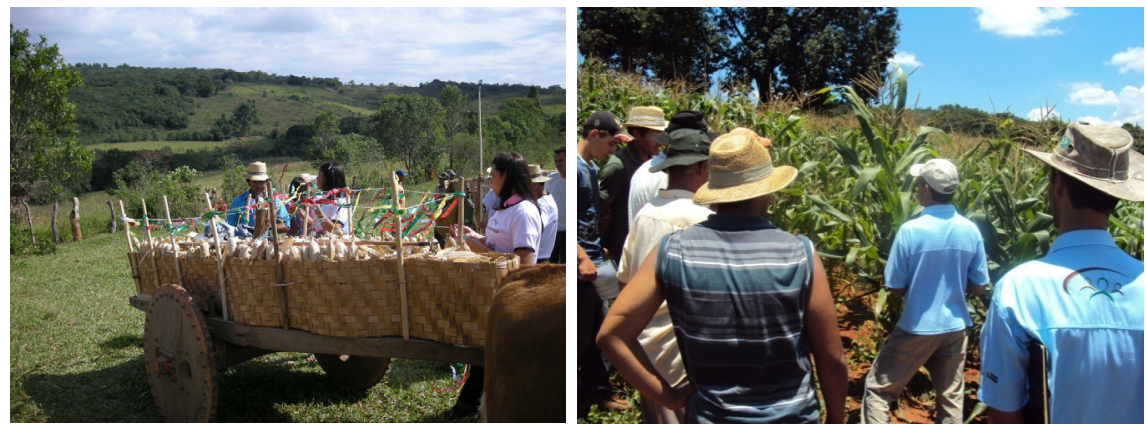

Figura 1. Fotos do dia de campo e do transporte da colheita de milho usando carros de boi, 2011. 


\section{REFERÊNCIAS BIBLIOGRÁFICAS}

COMPANHIA NACIONAL DE ABASTECIMENTO. Acompanhamento da safra de Brasileira de grãos: milho total ( $1^{a}$ e $2^{a}$ safra), Julho/2012. Disponível em: <http://www.conab.gov.br>. Acesso em 05 de julho de 2012.

HALLAUER, A.R.; CARENA, M.J.; MIRANDA FILHO, J.B. Quantitative genetics in maize breeding. New York: Springer, 2010.

PATERNIANI, E.; CAMPOS, M.S. Melhoramento do milho. In: Borém, A. (Ed.) Melhoramento de espécies cultivadas. Viçosa: UFV, 1999.

SOUZA SOBRINHO, F.; RAMALHO, M.A.P.; SOUZA, J.C. Genetic Diversity and inbreeding potential of maize commercial hybrids. Maydica (Bergamo), v.46, p.171-175, 2001. 
66 Revista ELO - Diálogos em Extensão Volume 01, número 01 - dezembro de 2012 